\title{
Comunicação
}

\section{Qualidade dos frutos de genótipos de tomateiro do Banco de Germoplasma de Hortaliças da Universidade Federal de Viçosa}

\author{
André Pugnal Mattedi ${ }^{1}$; Marcelo de Almeida Guimarães ${ }^{2 *}$; Derly José Henriques da Silva ${ }^{3}$ \\ Fabiano Ricardo Brunele Caliman ${ }^{4}$; Bruno Garcia Marim ${ }^{3}$
}

\section{RESUMO}

Foi avaliada a qualidade dos frutos de 29 acessos de tomateiro do Banco de Germoplasma de Hortaliças (BGH-UFV) e de três cultivares comerciais, Santa Clara, Débora Plus e Fanny. As variáveis avaliadas foram: sólidos solúveis (SS), acidez titulável (AT), pH e relação SS/AT. Foi observada, para os acessos, variação significativa das características avaliadas, com exceção do pH. Os acessos BGH700, BGH2000, BGH2008, BGH2013, BGH2014 e BGH2017 destacaramse no que se refere ao teor de SS, tendo estes sido superiores em $4,2^{\circ} \mathrm{Brix}$ aos dos cultivares comerciais. Com relação à acidez titulável, os acessos BGH2013, BGH2019, BGH2020 e BGH2033 apresentaram os maiores valores, com acidez acima de $0,57 \%$. Os cultivares comerciais foram alocados no grupo de menor acidez, com valores inferiores a $0,46 \%$. Para a relação SS/AT, destacaram-se os acessos BGH700, BGH2000, BGH2008 e o cultivar comercial Débora Plus com valores de 11,1; 11,9; 10,9; e 10,0, respectivamente.

Palavras-chave: Solanum lycopersicon Mill, sólidos solúveis, pH, pós-colheita.

\section{ABSTRACT \\ Fruit quality of tomato genotypes from the Vegetable Germplasm Bank at the Universidade Federal de Viçosa}

Fruit quality of 29 tomato accesses from the Vegetable Germplasm Bank of the Universidade Federal de Viçosa and three commercial cultivars, Santa Clara, Débora Plus and Fanny were evaluated for the characteristics soluble solids (SS), acidity (AT), $\mathrm{pH}$ and SS/AT ratio (flavor fruits indicator). The accesses showed significant variation for the evaluated characteristics, except for the $\mathrm{pH}$. The accesses BGH-700, BGH-2000, BGH-2008, BGH-2013, BGH-2014 and BGH-2017 stood out for the SS content, which were higher than $4.2^{\circ}$ Brix and the SS content of the commercial cultivars. Acidity of the accesses BGH-2013, BGH-2019, BGH-2020 and BGH-2033 was higher, above 0.57\%. The commercial cultivars were classified into the group with the lowest acidity, with values under $0.46 \%$. The accesses BGH-700, BGH2000, BGH-2008 and the commercial cultivar Débora Plus stood out for the SS/AT ratio, with values of 11.1, 11.9 and 10.9 , and 10.0, respectively.

Key words: Solanum lycopersicon L., soluble solids, $\mathrm{pH}$ and post-harvest.

\footnotetext{
Recebido para publicação em 28/10/2010 e aprovado em 28/07/2011

${ }^{11}$ Engenheiro-Agrônomo, Mestre. Estudante de doutorado em Genética e Melhoramento, Universidade Federal de Viçosa, Avenida Peter Henry Rolfs, s/n, Campus Universtitário, 36570-000, Viçosa, MG, Brasil. andremattedi@gmail.com,

${ }^{2 *}$ Engenheiro-Agrônomo, Doutor. INC-BC/Universidade Federal do Amazonas, Rua 1º de maio, Colônia, 69630-000, Benjamin Constant, AM, Brasil. mguimara@ hotmail.com (autor para correspondência)

${ }^{3}$ Engenheiro-Agrônomo, Doutor. Universidade Federal de Viçosa, Avenida Peter Henry Rolfs, s/n, Campus Universitário, 36570-000, Viçosa, MG, Brasil. derly@ufv.br, bgmarim@yahoo.com.br

${ }^{4}$ Engenheiro-Agrônomo, Doutor. Instituto de Educação, Ciência e Tecnologia do Espírito Santo, Campus Venda Nova do Imigrante, Rua Elizabeth Minete Perin, s/n, São Rafael, 29375-000, Venda Nova do Imigrante, ES, Brasil. frcaliman@ifes.edu.br
} 


\section{INTRODUÇÃO}

O tomateiro (Solanum lycopersicon Mill.) é uma das hortaliças mais cultivadas no mundo e, no Brasil, é a segunda mais importante, superada apenas pela batateira (Agrianual, 2007). No ano de 2009, as lavouras de tomateiro ocuparam área de 67.690 ha, produzindo 4.310.477 toneladas de fruto, sendo este cultivo distribuído em boa parte dos estados brasileiros (IBGE, 2009).

Por sua importância, a cultura do tomateiro tem sido muito estudada, especialmente no que diz respeito ao aumento da produtividade (Marim et al., 2005; Guimarães et al., 2007; Guimarães et al. 2008; Charlo et al. 2009; Wamser et al. 2009) e à obtenção de genótipos mais produtivos (Castro et al., 2010). Todavia, além da produtividade, deve-se ressaltar também a qualidade organoléptica e nutricional dos frutos. Embora os aspectos visuais (forma e cor) e físico (firmeza) sejam os principais influenciadores do consumidor no momento da compra dos produtos, tem-se observado preferência da população por produtos com melhor sabor e composição nutricional, atributos estes relacionados, principalmente, com os compostos aromáticos, açúcares e ácidos (Grierson \& Kader, 1986).

Para a maioria das frutas e hortaliças, entre elas o tomateiro, há poucas referências para o consumidor, pois são raras as marcas no mercado, o que impede que seja criado vínculo entre o consumidor e um determinado produto. Neste caso, se o fruto for de boa aparência, mas não agradar no que se refere ao sabor, não haverá estímulo para o consumo, pois sem satisfação, não há compra futura (Gutierrez \& Almeida, 2007).

A dificuldade do melhoramento genético para desenvolver um cultivar que tenha alta produtividade, aliada a um bom sabor, tornam escassos no mercado os cultivares que sejam promissores, tanto do ponto de vista produtivo, quanto da qualidade dos frutos (Mattedi et al., 2007). Uma alternativa viável para se chegar a tal objetivo é recorrer à ampliação da base genética da espécie, via programas de melhoramento. Isto porque a manifestação do potencial qualitativo e quantitativo de uma espécie depende da interação genótipo x ambiente, sendo a seleção do material genético, crucial para o sucesso da espécie em determinado ambiente (Freire et al., 2009).

O melhoramento genético pode buscar genes de interesse em diferentes espécies do gênero Lycopersicon visando, assim, à melhoria da qualidade dos frutos, sem que seja perdida a capacidade produtiva das plantas. Stevens \& Rick (1986) relatam que características específicas das espécies selvagens de Lycopersicon têm sido muito estudadas e utilizadas com o objetivo de melhorar o tomate, destacando estudos para cor e sabor dos frutos. Giordano et al. (2003) mostram as prin- cipais contribuições de diferentes espécies de Lycopersicon para os programas de melhoramento, destacando-se, entre elas, as relacionadas com a qualidade do fruto, com os genes alc (relacionado com a conservação pós-colheita do fruto), $B$ (alto teor de $\beta$-caroteno), $h p$ (alto teor de pigmentos), $u$ (amadurecimento uniforme), entre outros.

Sendo assim, os bancos de germoplasma são fontes muito importantes para ampliação da base genética de espécies, pois, por possuírem genótipos coletados em diferentes épocas e regiões do mundo, podem apresentar acessos com características diversas, quando comparados a um determinado genótipo considerado padrão comercial (Silva et al., 2008; Guimarães et al., 2010; Souza Sobrinho et al., 2010).

No entanto, a possibilidade de utilização de acessos de bancos de germoplasma como fonte de genes de interesse torna necessária sua caracterização, já que, na maioria dos casos, têm-se numerosas coleções sem, no entanto, conhecer seu real potencial como fonte doadora de genes para programas de melhoramento. Dessa forma, o objetivo deste trabalho foi caracterizar a qualidade dos frutos de acessos de tomateiro do Banco de Germoplasma de Hortaliças da Universidade Federal de Viçosa (BGH-UFV) e de cultivares comerciais.

\section{MATERIAL E MÉTODOS}

O experimento foi conduzido no Campo Experimental do Departamento de Fitotecnia da Universidade Federal de Viçosa. Foram utilizados 29 acessos do BGH-UFV e, como testemunhas, os cultivares comerciais Débora Plus, Santa Clara e Fanny. Os acessos utilizados são provenientes de expedições realizadas por pesquisadores nas décadas de 60, 70, 80, para formação do atual Banco de Germoplasma (Tabela I).

O delineamento experimental utilizado foi o de blocos casualizados, com três repetições e três plantas úteis por parcela. As mudas foram produzidas em bandejas de poliestireno de 128 células, em fevereiro de 2004, sendo transplantadas quando possuíam, em média, quatro folhas definitivas. O solo foi arado, gradeado e corrigido de acordo com a recomendação de adubação para o Estado de Minas Gerais (Ribeiro et al., 1999).

Foi utilizado o tutoramento vertical com fitilho, sendo as plantas conduzidas com uma haste e podadas acima do sexto racimo (Marim et al., 2005). O espaçamento utilizado foi de $0,6 \times 1,1 \mathrm{~m}$, entre plantas e linhas, respectivamente. Foi utilizada irrigação localizada, no sistema de tubos gotejadores. Os tratos culturais (desbrotas, amarrio, capinas, dentre outros) foram realizados semanalmente, assim como as adubações de cobertura, via fertirrigação, com sulfato de amônio e cloreto de potássio. 
As avaliações das características de qualidade dos frutos foram realizadas no Laboratório de Manejo de Recursos Genéticos do Departamento de Fitotecnia, na Universidade Federal de Viçosa. Foram utilizados, nas análises das características de qualidade, três frutos provenientes do terceiro cacho, colhidos quando apresentavam mais de $75 \%$ de sua superfície vermelha. As variáveis de qualidade dos frutos avaliadas foram: a) teor de sólidos solúveis ( $\mathrm{SS}$, expresso em ${ }^{\circ} \mathrm{Brix}$ ) medido em refratômetro digital; b) acidez titulável (AT, expressa em $\%$ de ácido cítrico); c) pH; d) relação SS/AT. Para avaliação do teor de sólidos solúveis, acidez titulável e pH utilizou-se a metodologia de Pregolato \& Pregolato (1985).

As características de qualidade do fruto foram submetidas à análise de variância e análise de agrupamento univariado (procedimento de Scott-Knott a 5\% de probabilidade), utilizando-se o programa GENES (Cruz, 2001).

\section{RESULTADOS E DISCUSSÃO}

Pela análise de variância, observou-se existência de efeito significativo para as características avaliadas, o que indica a possibilidade de variabilidade genética entre os acessos de tomateiro do BGH-UFV e os cultivares comerciais (Tabela II).

Para a característica $\mathrm{pH}$, foram observados valores entre 3,87 e 5,09, não havendo diferença significativa entre os tratamentos (Tabela II). Os valores obtidos estão próximos aos observados por Stevens \& Rick (1986), que, trabalhando com diferentes genótipos de Lycopersicon esculentum, observaram valores de $\mathrm{pH}$ variando de 4,26 a 4,82 . No entanto, estes pesquisadores verificaram a existência de variação significativa para esta característica entre os diferentes genótipos estudados. No presente trabalho, observou-se, para os cultivares comerciais Fanny, Santa Clara e Débora Plus pH de 4,11, 4,22 e 4,19, respectivamente. Valores próximos foram obtidos por Guimarães et al. (2007, 2008), que, trabalhando com os cultivares Kyndio (Grupo Santa Cruz) e Fanny, verificaram pH de 4,34 e 4,28, respectivamente. Apesar de não haver diferença significativa, observaramse poucos acessos com valores de $\mathrm{pH}$ abaixo de 4,0, e apenas um com pH acima de 5,0 (BGH2026).

No que diz respeito ao teor de sólidos solúveis (SS) (Tabela II), foram observados valores entre $2,73^{\circ}$ Brix e

Tabela 1. Acessos do Banco de Germoplasma de Hortaliças da UFV com as respectivas origens, data de coleta e nome comum no momento da coleta

\begin{tabular}{|c|c|c|c|}
\hline Acessos & Origem & Coleta & Nome comum \\
\hline BGH-700 & Cuiabá, MT & $09 / 01 / 67$ & tomate tipo santa cruz \\
\hline BGH-2000 & Universidade de Purdue, USA & $01 / 11 / 66$ & tomate KQ forlios \\
\hline BGH-2002 & Universidade de Purdue, USA & $01 / 11 / 66$ & tomate PI 280597 \\
\hline BGH-2003 & Universidade de Purdue, USA & $01 / 11 / 66$ & tomate Vosliad \\
\hline BGH-2004 & Universidade de Purdue, USA & $01 / 11 / 66$ & tomate PI 280599 \\
\hline BGH-2006 & Universidade de Purdue, USA & $01 / 11 / 66$ & tomate 3212 SRS \\
\hline BGH-2008 & Universidade de Purdue, USA & $01 / 11 / 66$ & tomate IVV 145-1-1-2-1-11 \\
\hline BGH-2011 & Universidade de Purdue, USA & $01 / 11 / 66$ & tomate ES 58 \\
\hline BGH-2013 & Universidade de Purdue, USA & $01 / 11 / 66$ & tomate WV 252-1-1-1 \\
\hline BGH-2014 & Universidade de Purdue, USA & $01 / 11 / 66$ & tomate WV 289-1-4-1 \\
\hline BGH-2016 & Universidade de Purdue, USA & $01 / 11 / 66$ & tomate coleta $39-15$ \\
\hline BGH-2017 & Universidade de Purdue, USA & $01 / 11 / 66$ & tomate PI 263713 \\
\hline BGH-2018 & Universidade de Purdue, USA & $01 / 11 / 66$ & tomate PI 174211 \\
\hline BGH-2019 & Universidade de Purdue, USA & $01 / 11 / 66$ & tomate PI 280669 \\
\hline BGH-2020 & Universidade de Purdue, USA & $01 / 11 / 66$ & tomate PI 127805 \\
\hline BGH-2021 & Universidade de Purdue, USA & $01 / 11 / 66$ & tomate VQ Iroux \\
\hline BGH-2026 & Universidade de Purdue, USA & $01 / 11 / 66$ & tomate PI 127801 \\
\hline BGH-2027 & Universidade de Purdue, USA & $01 / 11 / 66$ & tomate $1260-1-2$ \\
\hline BGH-2029 & Universidade de Purdue, USA & $01 / 11 / 66$ & tomate Heinz 1630 \\
\hline BGH-2032 & Universidade de Purdue, USA & $01 / 11 / 66$ & tomate PI 112835 \\
\hline BGH-2033 & Universidade de Purdue, USA & $01 / 11 / 66$ & tomate Heinz 14456 \\
\hline BGH-2034 & Universidade de Purdue, USA & $01 / 11 / 66$ & tomate Heinz $14451 \mathrm{VF}$ \\
\hline BGH-2035 & Universidade de Purdue, USA & $01 / 11 / 66$ & tomate Cusda 65 B 310 \\
\hline BGH-2038 & Universidade de Purdue, USA & $01 / 11 / 66$ & tomate Mto 20-4-25 \\
\hline BGH-2039 (A) & Universidade de Purdue, USA & $01 / 11 / 66$ & tomate VF 14 (Amarelo) \\
\hline BGH-2039 (V) & Universidade de Purdue, USA & $01 / 11 / 66$ & tomate VF 14 (Vermelho) \\
\hline BGH-2041 & Universidade de Purdue, USA & $01 / 11 / 66$ & tomate Snowball \\
\hline BGH-2046 & Universidade de Purdue, USA & $01 / 11 / 66$ & tomate Snowball \\
\hline BGH-2048 & Universidade de Purdue, USA & $01 / 11 / 66$ & tomate Coemell 61-37 \\
\hline
\end{tabular}


4,73 ${ }^{\circ}$ Brix, havendo formação de quatro grupos distintos, de acordo com o método de Scott-Knott. Os cultivares comerciais Fanny e Santa Clara foram alocados no terceiro grupo (c), com teor de SS de 4,11 ${ }^{\circ}$ Brix e 4,22 ${ }^{\circ}$ Brix, respectivamente. $\mathrm{O}$ cultivar Débora Plus foi alocado no segundo grupo (b), com teor de $\mathrm{SS}$ de $4,03^{\circ}$ Brix. Entre os acessos, foram destacados o BGH700, BGH2000, BGH2008, BGH2013, BGH2014 e BGH2017, com teor de SS acima de 4,23 ${ }^{\circ}$ Brix, compondo o primeiro grupo (a). Para a indústria, o teor de SS é importante, pois quanto maior, melhor será a consistência do produto processado e maior será o rendimento industrial, quando o objetivo é a desidratação e a concentração para a produção de molhos, estratos, catchup entre outros, relata Carvalho (1980).

Para a produção destinada à mesa, o teor de SS é importante, já que em sua composição predominam os açú- cares e ácidos e o balanço entre esses compostos é que irá determinar o sabor do fruto (Davies \& Hobson, 1981). Convém ressaltar que os acessos pertencentes ao grupo "a" possuem teor de SS médio acima $(4,54)$ dos observados nos frutos dos cultivares comerciais Fanny $(3,60)$, Santa Clara $(3,53)$ e Débora Plus $(4,03)$. Entre os cultivares existentes no mercado, observa-se significativa variação no teor de SS. Guimarães et al. (2007), trabalhando com o cultivar comercial de tomate Kyndio, verificaram valores médios de SS de 4,34.

Observou-se também variabilidade entre os acessos e cultivares, analisados quanto à variável AT, com formação de três grupos (Tabela II). Os acessos BGH2013, BGH2019, BGH2020 e BGH2033 foram os mais ácidos, com 0,60, 0,57, 0,62 e $0,60 \%$, respectivamente. As testemunhas comerciais foram alocadas no grupo "c", no qual estão os genótipos

Tabela 2. Médias das características pH, sólidos solúveis (SS), acidez titulável (AT) e relação SS/AT dos frutos de 29 acessos do BGH-UFV e três cultivares comerciais

\begin{tabular}{|c|c|c|c|c|}
\hline Acessos e cultivares & pH & SS $\left({ }^{\circ}\right.$ Brix $)$ & AT & SS/AT \\
\hline BGH-700 & 4,07 & $4,50 \mathrm{a}$ & $0,407 \mathrm{c}$ & $11,13 \mathrm{a}$ \\
\hline BGH-2000 & 4,37 & $4,23 \mathrm{a}$ & $0,355 \mathrm{c}$ & $11,92 \mathrm{a}$ \\
\hline BGH-2002 & 3,87 & $2,96 \mathrm{~d}$ & $0,511 \mathrm{~b}$ & $5,95 \mathrm{c}$ \\
\hline BGH-2003 & 3,97 & $3,26 \mathrm{~d}$ & $0,466 \mathrm{c}$ & $7,11 \mathrm{c}$ \\
\hline BGH-2004 & 4,24 & $3,63 \mathrm{c}$ & $0,479 \mathrm{~b}$ & $7,62 \mathrm{c}$ \\
\hline BGH-2006 & 4,19 & $3,16 \mathrm{~d}$ & $0,378 \mathrm{c}$ & $8,41 \mathrm{~b}$ \\
\hline BGH-2008 & 4,24 & $4,46 \mathrm{a}$ & $0,439 \mathrm{c}$ & $10,86 \mathrm{a}$ \\
\hline BGH-2011 & 4,14 & $3,56 \mathrm{c}$ & $0,476 \mathrm{~b}$ & $7,50 \mathrm{c}$ \\
\hline BGH-2013 & 4,22 & $4,73 \mathrm{a}$ & $0,597 \mathrm{a}$ & $8,21 \mathrm{c}$ \\
\hline BGH-2014 & 4,03 & $4,83 \mathrm{a}$ & $0,524 \mathrm{~b}$ & $9,26 \mathrm{~b}$ \\
\hline BGH-2016 & 4,14 & $3,96 \mathrm{~b}$ & $0,503 \mathrm{~b}$ & $7,93 \mathrm{c}$ \\
\hline BGH-2017 & 3,89 & $4,46 \mathrm{a}$ & $0,524 \mathrm{~b}$ & $8,53 \mathrm{~b}$ \\
\hline BGH-2018 & 4,07 & $3,16 \mathrm{~d}$ & $0,361 \mathrm{c}$ & $8,74 \mathrm{~b}$ \\
\hline BGH-2019 & 4,07 & $3,33 \mathrm{c}$ & $0,570 \mathrm{a}$ & $5,87 \mathrm{c}$ \\
\hline BGH-2020 & 3,88 & $3,46 \mathrm{c}$ & $0,615 \mathrm{a}$ & $5,69 \mathrm{c}$ \\
\hline BGH-2021 & 4,11 & $3,60 \mathrm{c}$ & $0,413 \mathrm{c}$ & $8,97 \mathrm{~b}$ \\
\hline BGH-2026 & 5,09 & $3,33 \mathrm{c}$ & $0,348 \mathrm{c}$ & $9,57 \mathrm{~b}$ \\
\hline BGH-2027 & 4,21 & $3,50 \mathrm{c}$ & $0,484 \mathrm{~b}$ & $7,26 \mathrm{c}$ \\
\hline BGH-2029 & 3,99 & $3,23 \mathrm{~d}$ & $0,448 \mathrm{c}$ & $7,22 \mathrm{c}$ \\
\hline BGH-2032 & 3,96 & $4,23 \mathrm{~b}$ & $0,538 \mathrm{~b}$ & $7,88 \mathrm{c}$ \\
\hline BGH-2033 & 4,15 & $4,13 \mathrm{~b}$ & $0,602 \mathrm{a}$ & $6,86 \mathrm{c}$ \\
\hline BGH-2034 & 4,18 & $3,63 \mathrm{c}$ & $0,415 \mathrm{c}$ & $8,74 \mathrm{~b}$ \\
\hline BGH-2035 & 4,11 & $3,50 \mathrm{c}$ & $0,474 \mathrm{~b}$ & $7,38 \mathrm{c}$ \\
\hline BGH-2038 & 4,12 & $3,46 \mathrm{c}$ & $0,406 \mathrm{c}$ & $8,55 \mathrm{~b}$ \\
\hline BGH-2039 Amarelo & 4,18 & $2,73 \mathrm{~d}$ & $0,366 \mathrm{c}$ & $7,45 \mathrm{c}$ \\
\hline BGH-2039 Vermelho & 4,11 & $3,10 \mathrm{~d}$ & $0,346 \mathrm{c}$ & $9,08 \mathrm{~b}$ \\
\hline BGH-2041 & 4,17 & $3,53 \mathrm{~d}$ & $0,460 \mathrm{c}$ & $7,67 \mathrm{c}$ \\
\hline BGH-2046 & 4,07 & $2,93 \mathrm{~d}$ & $0,449 \mathrm{c}$ & $6,68 \mathrm{c}$ \\
\hline BGH-2048 & 4,09 & $3,00 \mathrm{~d}$ & $0,429 \mathrm{c}$ & $7,08 \mathrm{c}$ \\
\hline Fanny & 4,11 & $3,60 \mathrm{c}$ & $0,458 \mathrm{c}$ & $7,87 \mathrm{c}$ \\
\hline $\mathrm{St}^{\mathrm{a}}$ Clara & 4,22 & $3,53 \mathrm{c}$ & $0,409 \mathrm{c}$ & $8,66 \mathrm{~b}$ \\
\hline Débora Plus & 4,19 n.s. & $4,03 \mathrm{~b}$ & $0,403 \mathrm{c}$ & $10,02 \mathrm{a}$ \\
\hline Média geral & 4,14 & 3,66 & 0,48 & 8,18 \\
\hline $\mathrm{CV}(\%)$ & 7,47 & 8,30 & 12,66 & 12,34 \\
\hline
\end{tabular}

Médias, seguidas pela mesma letra na coluna, não diferem telo teste de Scott-Knott a 5\% de probabilidade. n.s. - não significativo 
com menor acidez de frutos. Segundo Kader et al. (1978) e Mencarelli \& Salveit Jr. (1988), os frutos de tomate de alta qualidade devem possuir valores de acidez superiores a 0,32\%. A acidez é importante, pois mede a quantidade de ácidos orgânicos presentes na polpa dos frutos, que por sua vez está relacionada com a adstringência e sabor (Silva $\&$ Giordano, 2000). A AT dos frutos analisados variou de 0,35 a $0,62 \%$, sendo que metade dos acessos avaliados possuíam AT entre 0,4 e 0,5\%. Sampaio \& Fontes (1998) analisaram frutos do cultivar Santa Clara e observaram acidez variando de 0,29 a 0,33\%. Carvalho et al. (2005) observaram AT de 0,39, 0,40 e 0,41\% em frutos dos cultivares Andrea, Débora Max e Carmen, respectivamente.

Foi observada diferença significativa para a relação SS/AT, havendo formação de três grupos distintos (Tabela II). A relação SS/AT variou de 5,69 a 11,92. Segundo Mencarelli \& Saltveit Jr. (1988), frutos de alta qualidade são caracterizados por conter AT superior a $0,32 \%$, e SS acima de $3 \%$ e razão SS/AT maior que 10 . A relação SS/AT tem sido utilizada como um indicador para o sabor dos frutos do tomateiro e, de acordo com os resultados obtidos, observou-se a existência de acessos saborosos, como o BGH700, BGH2000, BGH2008, com relação SS/AT de 11,13, 11,92 e 10,86, respectivamente, e de bom sabor, caso do cultivar comercial Débora Plus, com relação SS/ AT de 10,02. O cultivar Santa Clara foi alocado no grupo "b", no qual estão os genótipos com relação SS/AT intermediária e o cultivar Fanny foi alocado no grupo "c", onde estão os acessos cujos frutos possuem as mais baixas relações SS/AT, com destaque para o acesso BGH2002, com a menor relação SS/AT $(5,95)$.

Segundo Jones Júnior (1999), elevado teor de ácidos e baixo teor de açúcares resultam em frutos de sabor ácido, enquanto elevado teor de açúcares e baixo teor de ácidos proporcionam sabor suave. Quando ambos, açúcares e ácidos, são reduzidos, o fruto torna-se insípido. Desta forma, os acessos BGH700, BGH2000 e BGH2008 possuem sabores suaves, uma vez que obtiveram alto teor de açúcares e baixo teor de ácidos e, a testemunha Débora Plus, que é considerado um dos cultivares do grupo Santa Cruz de melhor sabor no mercado atual, tende a apresentar sabor mais ácido que os demais acessos, por possuir menor teor de açúcar e baixo teor de ácido (Tabela II).

\section{CONCLUSÃO}

Conclui-se que os acessos do BGH-UFV possuem potencial genético para serem utilizados em programas de melhoramento que visem ao aumento da qualidade do fruto, e que os acessos BGH700, BGH2000 e BGH2008 destacaram-se para a característica SS/AT, sendo, portanto, promissores para programas de melhoramento genético visando à melhoria de sabor dos frutos.

\section{AGRADECIMENTOS}

Os autores agradecem, ao CNPq, pela concessão de bolsa de estudos, e à FAPEMIG, pelo suporte financeiro.

\section{REFERÊNCIAS}

Agrianual (2007) Anuário da Agricultura Brasileira. São Paulo, FNP Consultoria e Comércio. 520p.

Carvalho VD (1980) Características químicas e industriais do tomate. Informe Agropecuário, 66:63-68.

Carvalho LA, Neto JT, Arruda MC, Jacomino AP \& Melo PCT (2005) Caracterização físico-química de híbridos de tomate de crescimento indeterminado em função do espaçamento e número de ramos por planta. Revista Brasileira de Agrociência, 11:295-298.

Castro JPA, Nick C, Milagres CC, Mattedi AP, Marim BG \& Silva DJH (2010) Genetic diversity among tomato's subsamples for pre-breeding. Crop Breeding and Applied Biotechnology, 10: 74-82.

Charlo HCO, Souza SC, Castoldi R \& Braz LT (2009) Desempenho e qualidade de frutos de tomateiro em cultivo protegido com diferentes números de hastes. Horticultura Brasileira, 27: 144-149.

Cruz CD (2001) Programa Genes: versão Windows. Viçosa, UFV, $442 \mathrm{p}$.

Davies JN \& Hobson GE (1981) The constituents of tomato fruit - The influence of environment, nutrition, and genotype. Critical Reviews in Food Science and Nutrition, 15:204-280.

Freire AG, Oliveira FA, Carrilho MJSO, Oliveira MKT \& Freitas DC (2009) Qualidade de cultivares de alface produzida em condições salinas. Revista Caatinga, 22:81-88.

Giordano LB, Aragão FAS \& Boileus LS (2003) Melhoramento genético do tomateiro. Informe Agropecuário, 24:43-57.

Grierson D \& Kader AA (1986) Fruit ripening and quality. In:Atherton JG \& Rudich J (Eds). The tomato crop. A scientific basis for improvement. Londres, Chapman \& Hall, p. 241-280.

Guimarães MA, Silva DJH, Fontes PCR, Caliman FRB, Loos RA \& Stringheta PC (2007) Produção e sabor dos frutos de tomateiro submetidos à poda apical e de cachos florais. Horticultura Brasileira, 25:259-263.

Guimarães MA, Silva DJH, Fontes PCR \& Mattedi AP (2008) Produtividade e Sabor dos Frutos de Tomate do Grupo Salada em função de podas. Bioscience Journal, 24:32-38.

Guimarães LMS, Titon M, Lau D, Rosse LN, Oliveira LSS, Rosado CCG, Christo GGO \& Alfenas AC (2010) Eucalyptus pellita as a source of resistance to rust, ceratocystis wilt and leaf blight. Crop Breeding and Applied Biotechnology, 10:124-131.

Gutierrez ASD \& Almeida GVB (2007). Horticulturas - Sabor, aroma e aparência conquistam o consumidor. In: Anuário da Agricultura Brasileira. São Paulo, FNP Consultoria e Comércio, p. 347-348.

IBGE - Instituto Brasileiro de Geografia e Estatística (2009). Produção Agrícola Municipal: Culturas Temporárias e Permanentes. Rio de Janeiro, IBGE, 90p.

Jones Júnior JB (1999) Tomato Plant Culture: in the field, greenhouse and home garden. New York, CRC Press, 199p.

Kader AA, Morris LL, Stevens MA \& Albright-Holton M (1978) Composition and flavor quality of fresh market tomatoes as influenced by some postharvest handling procedures. Journal of American Society for Horticultural Science, 113:742-745.

Rev. Ceres, Viçosa, v. 58, n.4, p. 525-530, jul/ago, 2011 
Marim BG, Silva DJH, Guimarães MA \& Belfort G (2005) Sistemas de tutoramento e condução do tomateiro visando produção de frutos para consumo in natura. Horticultura Brasileira, 23: 951-955.

Mattedi AP, Soares BO, Almeida VS, Griolli JFJ, Silva LJ \& Silva DJH (2007) Introdução à cultura do tomateiro. In: Silva DJH \& Vale FXR (Eds). Tomate: Tecnologia de produção. Visconde do Rio Branco, Suprema, p.1-10.

Mencarelli F \& Salveit Júnior ME (1988) Ripening of maturegreen tomato fruit slices. Journal of American Society Horticultural Science, 113:742-745.

Pregolato W \& Pregolato DP (1985) Normas Analíticas do Instituto Adolfo Lutz. $3^{a}$ ed., São Paulo, Adolfo Lutz, 533p.

Ribeiro CR, Guimarães PTG \& Alvarez VH (1999) Recomendações para o uso de corretivos e fertilizantes em Minas Gerais. $5^{\text {a }}$ Aproximação, Viçosa, 359 p.

Sampaio RA \& Fontes PCR (1998) Qualidade de frutos de tomateiro fertirrigado com potássio em solo coberto com polietileno preto. Horticultura Brasileira, 16:136-139.
Silva JBC \& Giordano LB (2000) Tomate para processamento industrial. Embrapa Comunicação para Transferência de Tecnologia - Embrapa Hortaliças, Brasília, 168 p.

Silva RR, Gomes LAA, Monteiro AB, Maluf WR, Carvalho Filho JLS \& Massaroto JA (2008) Linhagens de alface-crespa para o verão resistentes ao Meloidogyne javanica e ao vírus mosaicoda-alface. Pesquisa Agropecuária Brasileira, 43:1349-1356.

Souza Sobrinho F, Auad AM \& Lédo FJS (2010) Genetic variability in Brachiaria ruziziensis for resistance to spittlebugs. Crop Breeding and Applied Biotechnology, 10:83-88.

Stevens MA \& Rick CM (1986) Genetics and breeding. In: Atherton JG \& Rudich J. The Tomato Crop: A scientific basis for improvement. New York, Chapman and Hall, p.35-110.

Wamser AF, Mueller S, Becker WF, Santos JP \& Suzuki A (2009) Espaçamento entre plantas e cachos por haste no tutoramento vertical do tomateiro. Horticultura Brasileira, 27:565-570. 